\title{
Carbon Flux of Down Woody Materials in Forests of the North Central United States
}

\author{
C. W. Woodall \\ USDA Forest Service, Northern Research Station, Saint Paul, MN 55108, USA \\ Correspondence should be addressed to C. W. Woodall, cwoodall@fs.fed.us \\ Received 9 June 2009; Revised 13 October 2009; Accepted 5 November 2009 \\ Academic Editor: Hamish Kimmins
}

Copyright ( $) 2010$ C. W. Woodall. This is an open access article distributed under the Creative Commons Attribution License, which permits unrestricted use, distribution, and reproduction in any medium, provided the original work is properly cited.

\begin{abstract}
Across large scales, the carbon (C) flux of down woody material (DWM) detrital pools has largely been simulated based on forest stand attributes (e.g., stand age and forest type). The annual change in forest DWM C stocks and other attributes (e.g., size and decay class changes) was assessed using a forest inventory in the north central United States to provide an empirical assessment of strategic-scale DWM C flux. Using DWM inventory data from the USDA Forest Service's Forest Inventory and Analysis program, DWM C stocks were found to be relatively static across the study region with an annual flux rate not statistically different from zero. Mean C flux rates across the study area were $-0.25,-0.12,-0.01$, and $-0.04(\mathrm{Mg} / \mathrm{ha} / \mathrm{yr})$ for standing live trees, standing dead trees, coarse woody debris, and fine woody debris, respectively. Flux rates varied in their both magnitude and status (emission/sequestration) by forest types, latitude, and DWM component size. Given the complex dynamics of DWM C flux, early implementation of inventory remeasurement, and relatively low sample size, numerous future research directions are suggested.
\end{abstract}

\section{Introduction}

For the purposes of this study, down woody materials (DWMs) are defined as detrital components of forest ecosystems comprising fine and coarse woody debris. Coarse woody debris (CWD) are pieces, or portion of pieces, of down dead wood with a minimum small-end diameter of at least $7.62 \mathrm{~cm}$ inches at the point of intersection with a sampling transect and a length of at least $0.91 \mathrm{~m}$. CWD pieces must be detached from a bole and/or not be self-supported by a root system with a lean angle more than 45 degrees from vertical [1]. Fine woody debris (FWD) are pieces, or portion of pieces, of down woody with a diameter less than $7.62 \mathrm{~cm}$ inches at the point of intersection with a sampling transect excluding dead branches attached to standing trees, dead foliage, bark fragments, or cubicle rot.

It has been estimated that 35 percent of the total forest carbon (C) pool in the U.S. is in live vegetation, 52 percent in the soil, and 14 percent in dead organic material, such as down woody materials (DWMs) [2]. Furthermore, it has been estimated that annual CWD and FWD carbon sequestration offset approximately 1 percent of all $\mathrm{CO}_{2}$ emissions in the United States [3]. Terrestrial forest C pools, such as FWD and CWD, often represent a balance between the influx of $\mathrm{CO}_{2}$ fixed in photosynthesis and the efflux of $\mathrm{CO}_{2}$ through woody decay processes [4]. The decay rates of any individual piece of forest dead wood is determined by substrate quality, microbial activity, air temperature, and available moisture [5]. Similarly, the productive capacity of any given forest is partially governed by climatic variables such as temperature [6]. Some studies have suggested that forest detritus production and decay may be in balance [7], whereas others have suggested that increased detritus decomposition rates due to climate change may ultimately cause forest detritus $\mathrm{C}$ pools to become net $\mathrm{CO}_{2}$ emitters $[8,9]$. Recently, Woodall and Liknes [10] have linked FWD and CWD C to climate and indicated that DWM's status as a C sink could be at risk in a world of warming temperatures and concomitant increases in precipitation.

Beyond sensitivity of DWM C stocks to climate change, at smaller spatial and temporal scales there is evidence that DWM C flux is related to stand development and disturbance processes (e.g., fire, density-induced mortality, and branch shedding). In western U.S. forests, fire is often listed as 
a control on DWM C stocks $[11,12]$, while in eastern U.S. forests stand development/management processes may correlate with DWM C flux dynamics $[13,14]$. It has been suggested that the dynamics of DWM C flux may be an important determinant as to whether conversion of oldgrowth to younger managed forests indeed sequester more C [15]. The empirical monitoring of DWM C flux has been achieved using diverse methods at various scales. At small scales, intensive site-specific field methods have been used to estimate the efflux of C from DWM pieces (e.g., see Gough et al. [14]). At larger scales, differences between forest inventories of DWM C at two points in time have been assumed to be the DWM C flux (e.g., see EPA [3]). Despite the higher levels of uncertainty associated with the latter flux monitoring methodology, DWM C flux estimates from forest inventories provide an opportunity to explore DWM C flux from the population perspective. Overall, largescale empirical assessments of DWM C flux are critical to estimating future U.S. C stock inventories, greenhouse gas offset accounting, and climate change mitigation efforts. The goal of this study is to assess the flux of C in DWM across the north central United States with specific objectives to (1) estimate mean C flux by small FWD, medium FWD, large FWD, and CWD for the entire study area, forest types, and classes of latitude, (2) estimate changes in plot-level CWD diameter and decay distributions as a means to interpret CWD C flux dynamics, (3) examine the relationship between standing live, dead, and down dead woody C stocks, and (4) forward suggestions for additional studies, analytical refinements, and implications of study results on current understanding of $\mathrm{C}$ flux dynamics.

\section{Methods}

2.1. Field Sample Protocols. The field and analytical procedures used to estimate DWM C flux define flux as the change in DWM C from time 1 (2002) to time 2 (2007) using a large-scale forest inventory conducted by the USDA Forest Service's Forest Inventory and Analysis (FIA) program. Although there are numerous methods for estimating annual DWM C flux, this study's methodology allows multistate analyses while unraveling flux dynamics that may be used in development of forest inventory $\mathrm{C}$ imputation models. FIA conducts a 3-phase inventory of forest attributes of the United States [16]. The FIA sampling design is based on a tessellation of the United States into hexagons approximately 2,428-ha in size with at least one permanent plot established in each hexagon. In phase 1, the population of interest is stratified and plots are assigned to strata to increase the precision of estimates. In phase 2 , tree and site attributes are measured for plots established in the 2,428-ha hexagons. Phase 2 plots consist of four $7.32 \mathrm{~m}$ fixed radius subplots on which standing live and dead trees are inventoried (for more information, see [17]).

DWMs are sampled during the third phase of FIA's multiscale inventory sampling design $[1,17]$. CWD are sampled on transects radiating from each FIA subplot center (at angles of 30, 150, and 270 degrees, resp.). Each subplot has three $7.32 \mathrm{~m}$ transects, totaling $87.8 \mathrm{~m}$ for a fully forested inventory plot. Information collected for every CWD piece intersected by transects is transect diameter, length, smallend diameter, large-end diameter, decay class, and species. Transect diameter is the diameter of a down woody piece at the point of intersection with a sampling transect. Decay class is a subjective determination of the amount of decay present in an individual log. Decay class 1 is the least decayed (freshly fallen $\log$ ), while decay class 5 is an extremely decayed log (cubicle rot pile). The species of each fallen log is identified through determination of species-specific bark, branching, bud, and wood composition attributes (excluding decay class five). FWD with transect diameters less than $0.61 \mathrm{~cm}$ (small FWD) and $0.62 \mathrm{~cm}$ to $2.54 \mathrm{~cm}$ (medium FWD) are tallied separately on a $1.83 \mathrm{~m}$ slope distance transect $(4.27 \mathrm{~m}$ to $6.09 \mathrm{~m}$ on the 150 -degree transect). FWD with transect diameters of $2.55 \mathrm{~cm}$ to $7.59 \mathrm{~cm}$ (large FWD) are tallied on a $3.05 \mathrm{~m}$ slope distance transect $(4.27 \mathrm{~m}$ to $7.32 \mathrm{~m}$ on the 150 degree transect).

2.2. Data and Analysis. DWM plots first established in 2002 were remeasured in 2007 for a total of 185 plots in the following states: IA (7), IL (11), IN (9), KS (7), MI (37), MN (30), MO (38), ND (2), NE (4), SD (6), WI (34) (see Figure 1). Individual CWD pieces were matched based on location $( \pm 0.6 \mathrm{~m}$ transect length) along the same sample transect in times 1 and 2. The volume and C content of FWD and CWD were determined through application of estimators detailed by Woodall and Monleon [1]. Briefly, for FWD the volume of FWD is estimated per unit area then converted to an estimate of biomass using a bulk density and decay reduction factor based on forest type. An estimate of FWD $\mathrm{C}$ is then derived by reducing the biomass estimate by 0.5 . For CWD the volume is determined for every CWD piece then used in an estimator to estimate per unit area volume. Volume is converted into biomass and $\mathrm{C}$ through the use of decay reduction factors, bulk density, and carbon conversion based on a piece's unique species and decay class [18]. Carbon flux for each DWM component was calculated as the difference in $\mathrm{C}$ between times 2 and 1 , divided by the number of years between inventories (measurement units $=\mathrm{Mg} / \mathrm{ha} / \mathrm{yr}$ ). The juxtaposition of the measurement times allowed calculation of flux using the widely accepted format that increases in $\mathrm{C}$ stocks to be negative indicating possible sequestration of $\mathrm{C}$. The means and associated standard errors of C flux by small FWD, medium FWD, large FWD, and CWD were estimated for the entire study area, forest types, and classes of latitude. In order to determine whether stand component flux rates were significantly different from zero, student vs $t$-tests were conducted (alpha $=0.1$ ).

Finally, the diameter and decay distributions of CWD were estimated at the plot level at times 1 and 2. This methodology differs from other DWM C flux analyses in this study as differences in individual CWD pieces were assessed. Through a CWD piece matching algorithm (for details see Westfall and Woodall [19]), differences in time 1 and time 2 decay class, total volume, large-end diameter, and carbon content estimates were estimated for individual CWD pieces ( $n=380$ pieces $)$. 


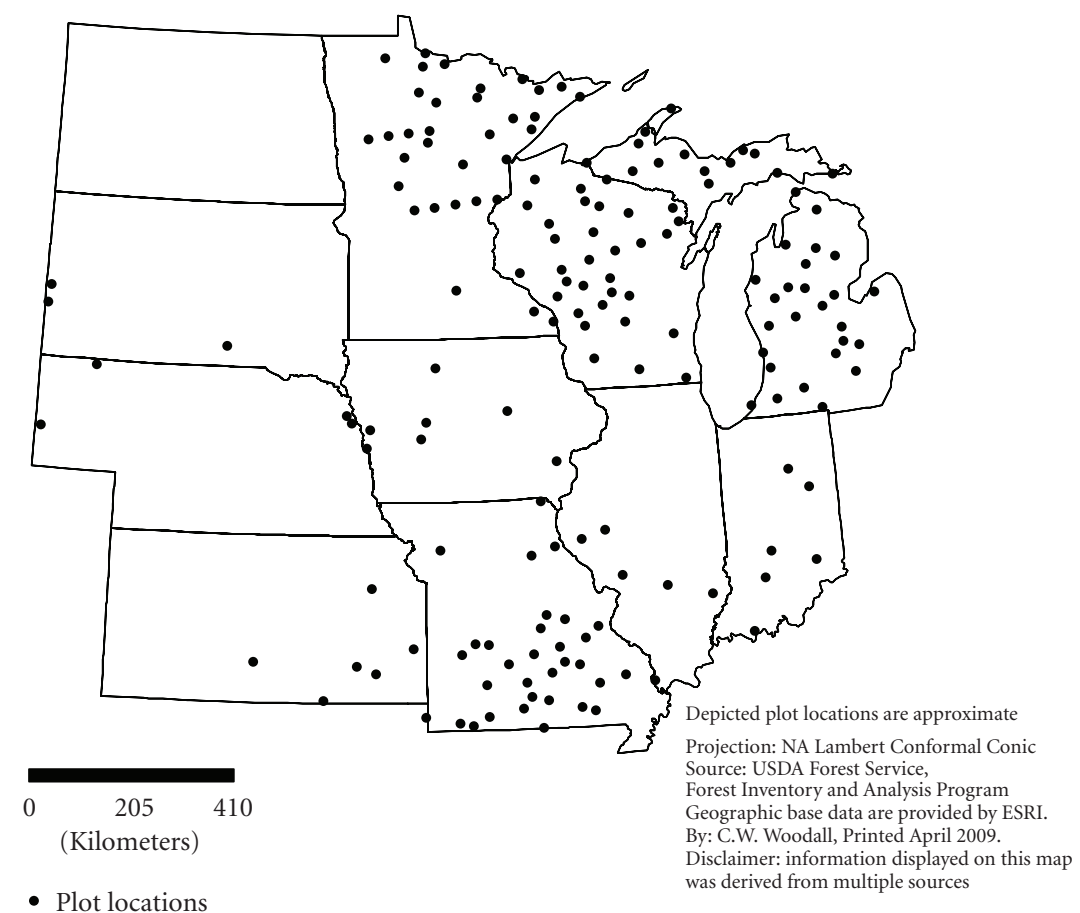

FIgURE 1: Study plot approximate locations across the north central United States, 2002 to 2007.

\section{Results}

All examined forest stand components (standing live/dead and CWD/FWD) sequestered net $\mathrm{C}$ during the 5-year period between measurements (Table 1). Standing live trees sequestered the most $\mathrm{C}$ with a mean of $-0.25 \mathrm{Mg} / \mathrm{ha} / \mathrm{yr}$ followed by standing dead trees with a mean of $-0.12 \mathrm{Mg} / \mathrm{ha} / \mathrm{yr}$. Together, standing live and standing dead trees accounted for nearly 90 percent of the annual sequestration. The minimal sequestration rates of FWD and CWD across the north central states were not statistically different from zero $(P$ values of.55 and.86, resp.). Sequestration rates varied widely by forest type with ranges in $\mathrm{C}$ flux rates for standing live, standing dead, FWD, and CWD being -1.85 to $1.48,-0.53$ to $1.21,-0.95$ to 0.71 , and -0.80 to $1.02 \mathrm{Mg} / \mathrm{ha} / \mathrm{yr}$, respectively (Table 2). There were no obvious patterns in flux among forest types nor among stand components within forest types.

There were very little discernible trends in C flux in FWD or CWD across latitude classes (Figure 2). The median C flux (Mg/ha/yr) of FWD changed from a net sequestration to a net emission/transfer from latitudes below 38 degrees to the 41-44-degree latitude class. From a net emission/transfer at the 41-44-degree latitude class, FWD C stocks once again sequestered C at latitudes above 47 degrees. It should be noted that the 95 th percentile of FWD $\mathrm{C}$ sequestration steadily decreased as latitude increased. The median annual flux of CWD hovered steadily around zero across all latitude classes. An interpolation of CWD and FWD flux across the north central states indicated some hotspots of emission/transfer (e.g., southeastern Missouri and central Indiana) and sequestration (e.g., northeastern Minnesota), possibly reflecting local disturbance events or recovery (i.e., rapid stand growth following stand initiation) (Figure 3).

Between 2002 and 2007, remeasured CWD (through utilization of matching algorithm) indicated an increase in the percentage of recently recruited CWD pieces $(\approx 30$ percent, CWD decay class 1$)$ along with a decrease in the percentage of highly decayed CWD pieces ( $\approx 15$ percent, decay class 5 ) (Figure 4(a)). In contrast, there were minimal changes in the distribution of CWD piece size class distribution between times one and two (Figure 4(b)). The exception is the largest transect diameter class $(>45.7 \mathrm{~cm})$ where there were less large CWD pieces in time $2(\approx 30$ percent).

Trends in standing live/dead and CWD/FWD annual C flux were examined across classes of stand age (15-year classes) (Figure 5). Standing live trees consistently provided a net sequestration of $\mathrm{C}$ across the remeasurement cycle at a regional scale with median values ranging between -0.91 and $-0.35 \mathrm{Mg} / \mathrm{ha} / \mathrm{yr}$. The median flux rates for standing dead trees, FWD, and CWD were all nearly zero across all age classes, although there was a slight tendency for FWD and CWD to provide net sequestration in younger age classes when compared to a tendency to be net emitters (or transfer to other forest stocks) in older age classes.

Refining comprehension of the relationship between both live and dead trees (standing and down) is important to unraveling of both stand and $\mathrm{C}$ flux dynamics. There are four scenarios with regards to these dynamics: (1) live emission/transfer and dead emission/transfer, (2) live sequestration and dead sequestration, (3) live emission/transfer 
TABLE 1: Mean stock density (time 1,2002) and average annual carbon flux for standing live/dead trees and down woody materials (fine and coarse) where a negative estimate indicates a net sequestration north central across the United States, 2002 to 2007 (obs = 182).

\begin{tabular}{|c|c|c|c|c|}
\hline Stock & Mean Carbon Stock Time 1 (Mg/ha) & Std. Err. $(\mathrm{Mg} / \mathrm{ha})$ & Mean Carbon Flux (Mg/ha/yr) & Std. Err. (Mg/ha/yr) \\
\hline Standing Live & 36.48 & 1.85 & -0.25 & 0.11 \\
\hline Standing Dead & 3.18 & 0.39 & -0.12 & 0.06 \\
\hline Coarse Woody Debris & 3.82 & 0.42 & -0.01 & 0.07 \\
\hline Fine Woody Debris & 2.91 & 0.21 & -0.04 & 0.06 \\
\hline Small Fine Woody Debris & 0.14 & 0.01 & 0.00 & 0.01 \\
\hline Medium Fine Woody Debris & 0.83 & 0.08 & -0.01 & 0.01 \\
\hline Large Fine Woody Debris & 1.94 & 0.16 & -0.03 & 0.06 \\
\hline
\end{tabular}

TABLE 2: Average annual carbon flux by forest type for down woody material components where $n>3$ : live (standing live trees), Sdead (standing dead trees), FWD (fine woody debris), and CWD (coarse woody debris) where a negative estimate indicates a net sequestration north central across the United States, 2002 to 2007.

\begin{tabular}{lccccccccc}
\hline Forest type & $n$ & Live & Std. Err. & Sdead & Std. Err. & FWD & Std. Err. & CWD & Std. Err. \\
\hline Red pine & 4 & -0.87 & 0.51 & -0.03 & 0.06 & -0.13 & 0.10 & -0.14 & 0.13 \\
Balsam fir & 4 & -0.17 & 0.71 & -0.36 & 0.42 & -0.18 & 0.11 & -0.34 & 0.18 \\
Black spruce & 4 & 0.44 & 0.43 & 0.10 & 0.06 & -0.09 & 0.05 & -0.80 & 0.75 \\
Northern white cedar & 7 & -0.30 & 0.23 & -0.05 & 0.05 & 0.13 & 0.08 & 0.27 & 0.15 \\
White/red oak and hickory & 31 & -0.03 & 0.32 & 0.05 & 0.13 & -0.13 & 0.10 & 0.23 & 0.19 \\
White oak & 10 & -0.91 & 0.09 & 0.00 & 0.02 & 0.19 & 0.08 & 0.17 & 0.24 \\
Elm/Ash/Black Locust & 12 & -0.42 & 0.16 & -0.46 & 0.16 & -0.68 & 0.74 & -0.75 & 0.43 \\
Mixed upland hardwoods & 10 & 0.46 & 0.76 & -0.53 & 0.68 & -0.12 & 0.19 & -0.20 & 0.24 \\
Black ash/American elm/red maple & 8 & -0.53 & 0.32 & -0.08 & 0.21 & 0.03 & 0.25 & 0.30 & 0.22 \\
Silver maple/American elm & 4 & -1.85 & 0.60 & -0.12 & 0.08 & -0.20 & 0.17 & -0.28 & 0.98 \\
Sugar maple/beech/yellow birch & 12 & 0.07 & 0.40 & -0.20 & 0.14 & 0.14 & 0.10 & 0.34 & 0.20 \\
Hard maple/basswood & 9 & -0.31 & 0.38 & -0.33 & 0.27 & -.20 & 0.12 & 0.14 & 0.39 \\
Aspen & 14 & -0.36 & 0.20 & -0.02 & 0.08 & 0.04 & 0.13 & 0.11 & 0.28 \\
Balsam poplar & 4 & -0.47 & 0.20 & -0.23 & 0.20 & 0.08 & 0.28 & 0.04 & 0.09 \\
\hline
\end{tabular}

and dead sequestration, and (4) live sequestration and dead emission/transfer. An important caveat when viewing these results is that a reduction in any given forest carbon pool $\mathrm{C}$ on any given site is not necessarily an emission. Often these C stocks transfer their $\mathrm{C}$ to another stock (e.g., live tree $\mathrm{C}$ transfer to DWM to soils). Thus, emissions are labeled as emission/transfer. For both standing and down dead trees, the most common occurrence is live sequestration and either emission/transfer or sequestration of dead wood $\mathrm{C}$ through decay processes (Figures 6(a) and 6(b)). It appears to be an infrequent event that both live and dead $C$ stocks are both net emitters of C. It is also uncommon that stands have net emission/transfer of live stocks but present net sequestration of dead wood stocks. The scale of flux does vary by scenario, excluding some obvious outliers, with the net live sequestration and net dead wood emission/transfer presenting the largest range in flux.

\section{Discussion}

This study is an initial assessment of DWM C flux using less than one fifth of the eventual remeasurement dataset for one region of the U.S. As such, important considerations may be made with respect to how to improve $\mathrm{C}$ flux estimation in future analyses. First, sampled forest conditions must be appropriately matched at two points in time. Land conversions, forest type changes, and disturbance events may greatly alter forest conditions, and thus, complicate change analysis techniques. Second, possibly a far larger issue for DWM C flux estimation is the differences in sample designs and lack of tracking individual dead wood pieces through time. Although the DWM sample design did not change between 2002 and 2007, other dead wood monitoring efforts in other regions/nations should focus efforts on utilizing identical sample designs for change estimation, rather than trying to adjust DWM estimators to avoid bias in change estimates. Third, even though the $\mathrm{C}$ flux of some DWM components may be fairly substantial, they all need to be couched in the inherent measurement error in these field inventories [20]. A $0.1 \mathrm{~cm}$ change in CWD large-end diameter may be negated by the measurement repeatability standard being $\pm 5.1 \mathrm{~cm}$ for field crews [19]. Fourth, the transition in $\mathrm{C}$ stocks from standing live to standing dead/CWD is not explicitly tracked. Carbon stocks 


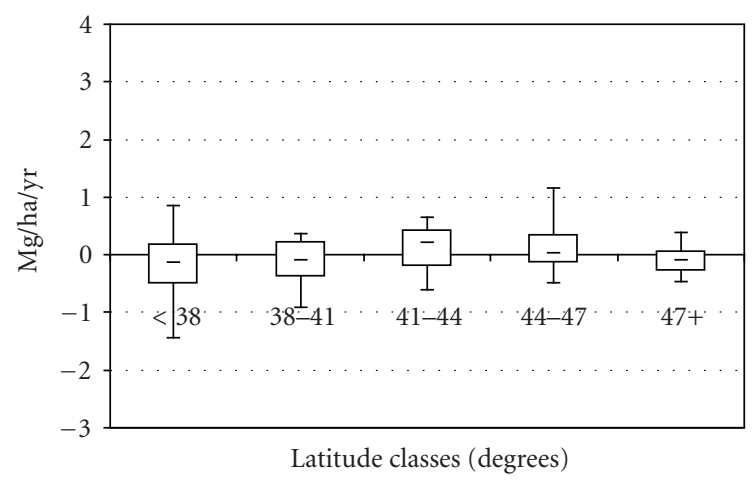

(a)

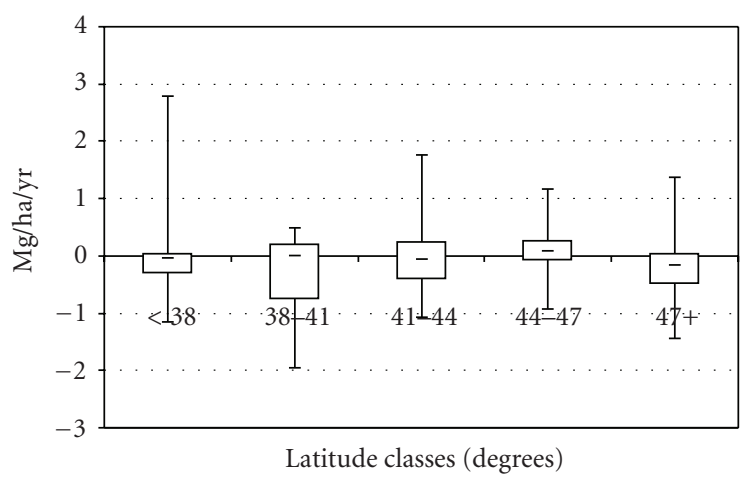

(b)

Figure 2: Box plots of carbon flux (Mg/ha/yr) by 3 degree latitude classes for (a) fine woody debris and (b) coarse woody debris across the north central United States, 2002 to 2007.

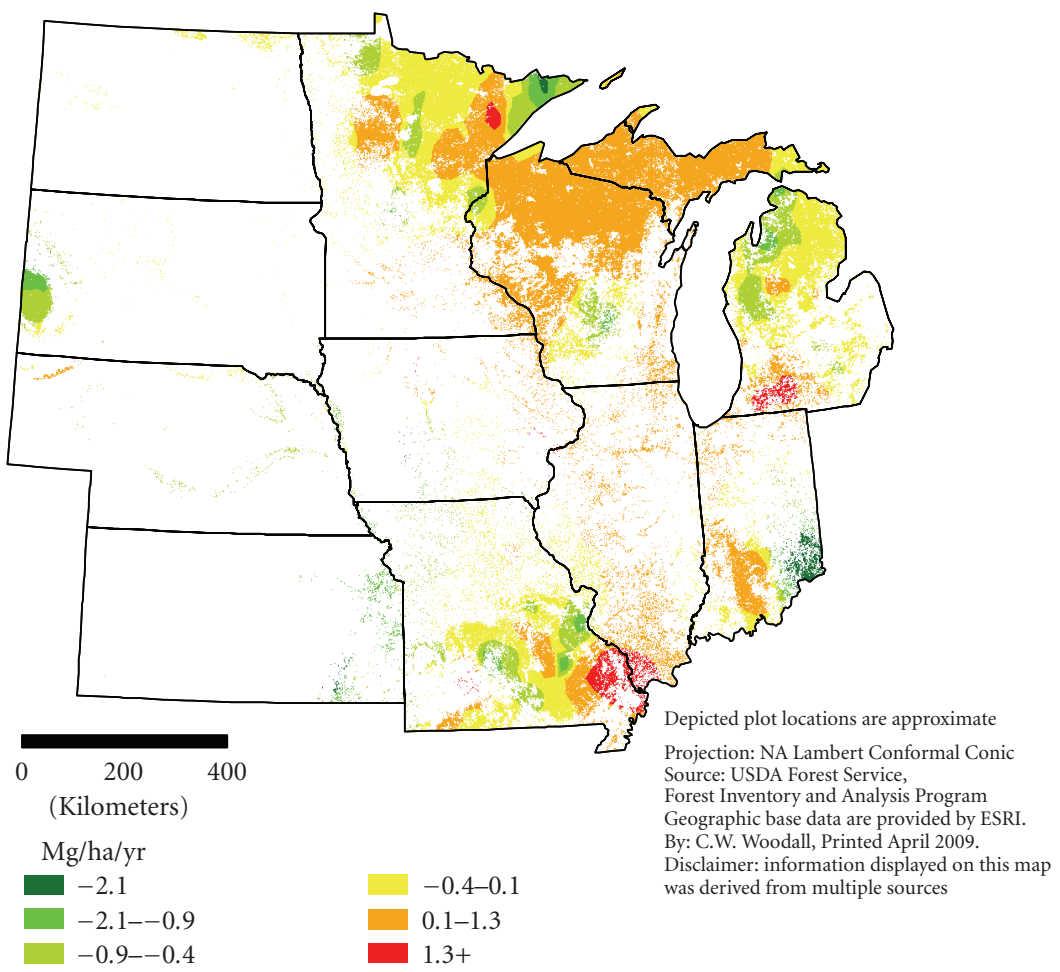

FIGURE 3: Interpolated surface (inverse distance weighting) of annual down dead wood carbon flux across the north central United States, 2002 to 2007.

were calculated at plot levels between time one and time two; therefore, it is entirely possible that a live tree in time one could die and fall outside the plot in time two. In reality, the forest ecosystem did not emit carbon immediately. Hence, there may be errors with tracking stocks of forest ecosystem C (e.g., standing dead or CWD) using forest inventories that may be additional to those commonly calculated (e.g., volume growth) for remeasured standing live trees. Finally, the unique stand disturbance history and live tree mortality attributes of forests may ultimately derive DWM C flux. As this study was as an initial analysis of large-scale DWM C flux, future examination of DWM C dynamics is suggested based on direction from emerging science [21]. Overall, further evaluation and resolution of these issues should provide a foundation for future work with larger datasets eventually replacing simulations currently used in national greenhouse gas assessments [20,22].

Despite the use of an initial dataset, preliminary DWM $\mathrm{C}$ flux hypotheses may be promulgated. First, how closely do the results of this systematic regional, wide study confirm the 


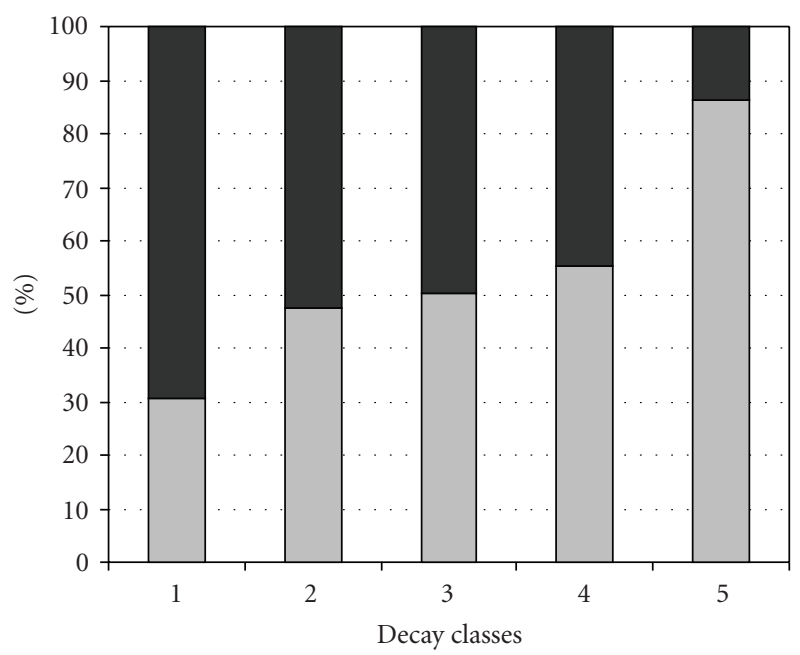

(a)

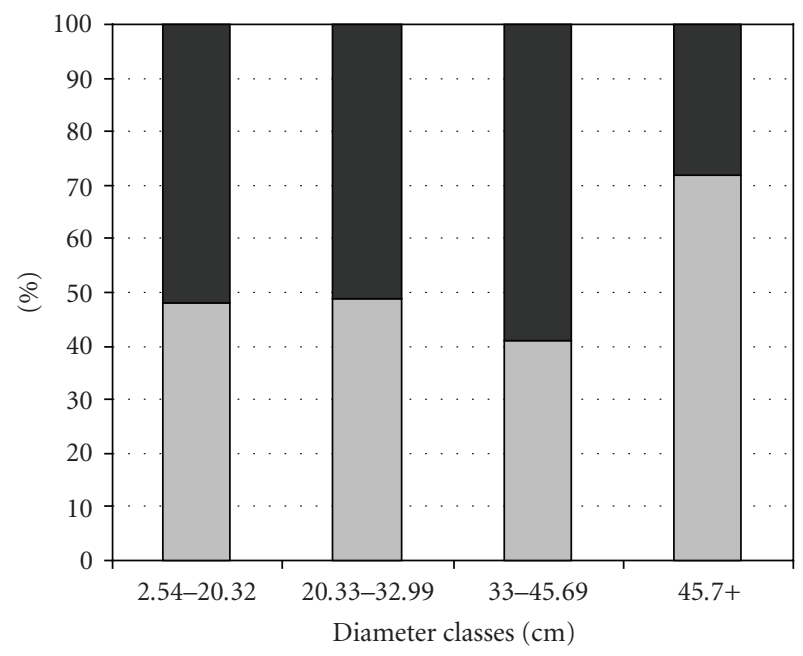

- Time 2,2007

Time 1,2002

(b)

FIgURE 4: Percentage of coarse woody debris pieces in time one (2002) and time two (2007) in (a) decay classes and (b) transect diameter class in the north central United States, 2002 to 2007.

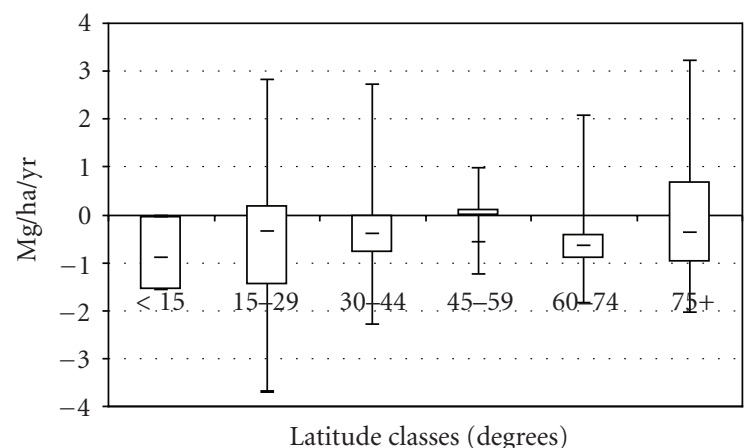

(a)

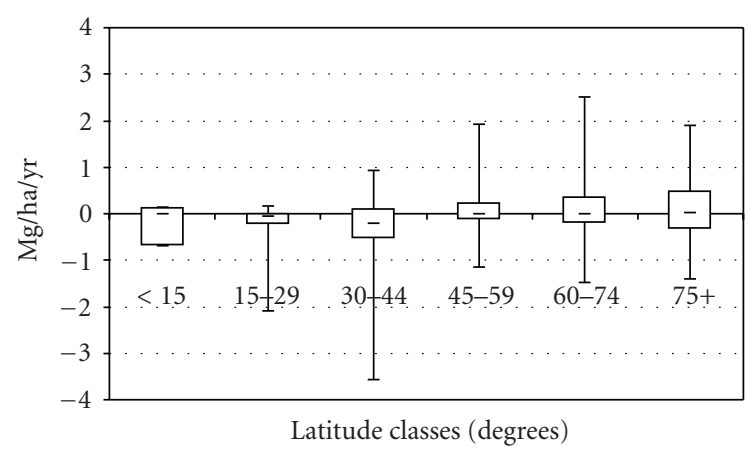

(c)

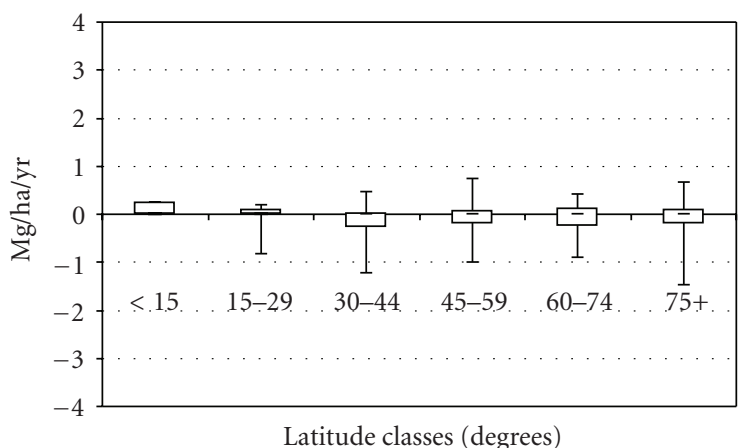

(b)

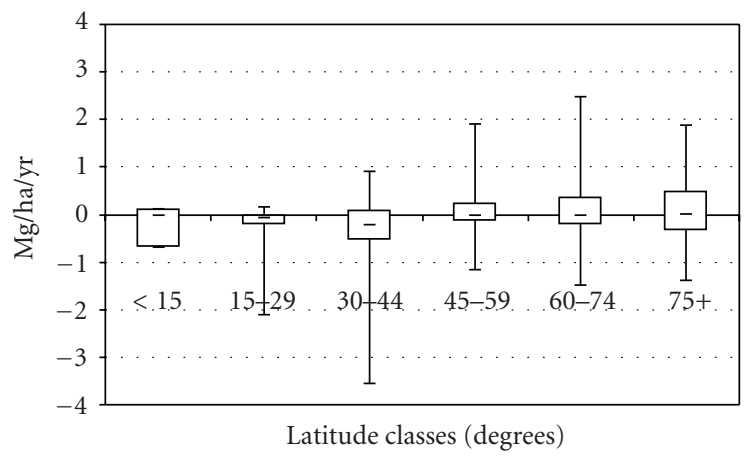

(d)

Figure 5: Box plots of carbon flux ( $\mathrm{Mg} / \mathrm{ha} / \mathrm{yr}$ ) by 15-year stand age classes for (a) standing live trees, (b) standing dead trees, (c) coarse woody debris, and (d) fine woody debris across the north central United States, 2002 to 2007. 
results of more intensive, yet spatially limited or simulated studies? Gough et al. [14] found an annual CWD flux of $-0.21 \mathrm{Mg} / \mathrm{ha} / \mathrm{yr}$ in a northern hardwood site in Michigan with decay classes four and five CWD pieces comprising a plurality of the sequestration. Most other studies have not explicitly tracked DWM C flux; rather they stated current DWM C stocks and expected residence times which ranged from 5.9 years for CWD in tropical forests [23] to many decades in higher latitude forests [11,24]. With this study's relative low CWD C flux rate, it may be hypothesized that north central CWD may have a long residence time, therefore affecting the regional forest carbon balance for decades as found in other forest ecosystems [12, 25, 26]. Woodall and Liknes [27] suggested that as the climate warms, increases in decay rates (emission) might more than offset dead wood C sequestration. This study found initial evidence that higher latitudes may be experiencing CWD C emission/transfer on some sites, while FWD C stocks may be remaining static. Standing live tree $\mathrm{C}$ stocks can easily increase in a stand with no regeneration simply by relying on individual tree increment. For DWM C stocks, it is a much different situation where the lack of DWM recruitment will always decrease their respective $\mathrm{C}$ stocks resulting in an emission/transfer of C.

Refinement of forest stand $\mathrm{C}$ dynamics may be gained by viewing $\mathrm{C}$ flux by stand component (e.g., standing live and CWD) across classes of stand age. At a regional level, there appear to be no strong trends across classes of stand age for any stand component. The most evident sequestration stand component is that of standing live trees, with the remainder of stand components displaying substantial variation. It does appear that younger stands (15-44 years) had a tendency to have greater fourth quartile sequestration rates in terms of all stand components when compared to older stands. It may be hypothesized that these middle-aged stands are fully stocked with tree biomass undergoing either stem exclusion or understory reinitiation [28]. In addition, the stage of stand development of these stands may have appreciable tree mortality and branch shedding increasing standing dead, CWD, and FWD C stocks. This study does not address the DWM C flux dynamics among stands converted to different stages of stand development and explicitly examined in other studies [15].

Examination of the scatter plots (Figure 6) of dead wood (both CWD and standing dead) versus standing live annual C flux can help indicate dynamics in both the scale (amount) of $\mathrm{C}$ flux and the frequency (Figure 7). In the north central U.S., it is a fairly uncommon event that there is both an emission/transfer of dead wood and standing live C. Most assuredly in other forest ecosystems prone to more frequent fire disturbances, this situation may be different (e.g., see $[12,26])$. It is also an uncommon occurrence that there is a live tree $\mathrm{C}$ emission/transfer with a dead wood sequestration. However, the scale of this flux can be greater than the previous example since there could be a substantial transfer in $\mathrm{C}$ from standing live to dead (e.g., widespread stand mortality event or clear cutting) [29]. The most common C dynamics scenario in north central U.S. forests is that of live tree sequestration and either an emission/transfer or

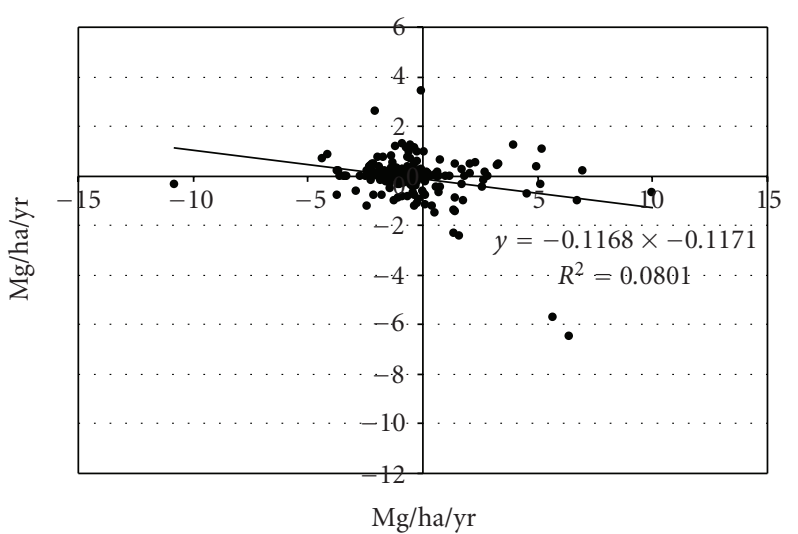

(a)

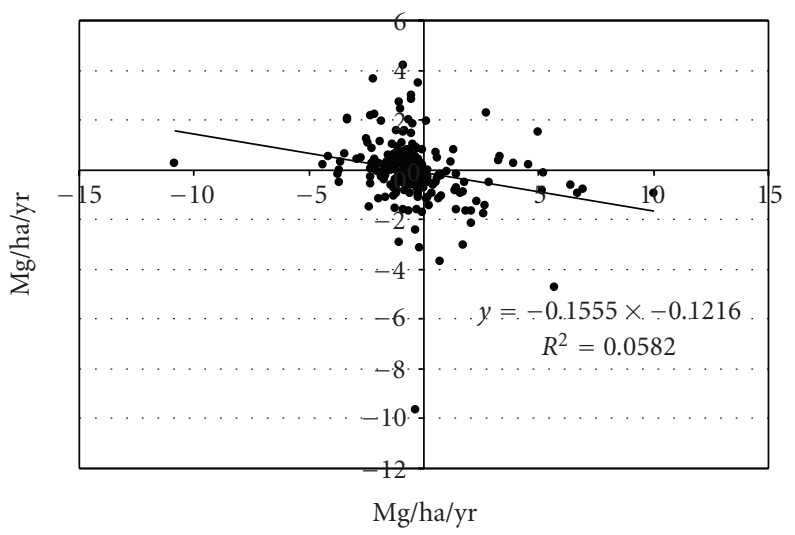

(b)

Figure 6: Scatter plots of (a) standing dead and (b) down dead woody material $\mathrm{C}$ stocks by standing live tree $\mathrm{C}$ stocks across the north central United States, 2002 to 2007.

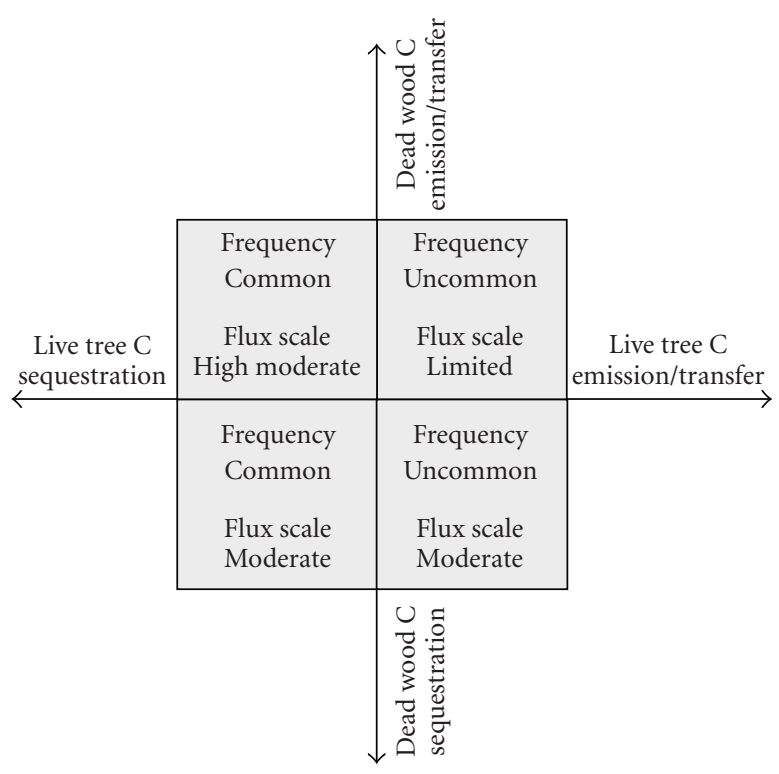

FIGURE 7: Theoretical relationship between standing live tree and dead tree $\mathrm{C}$ flux scales and frequencies. 
sequestration of dead wood C. If live trees are not dying, it appears that the scale of flux is greater for dead wood emission/transfer as compared to that of sequestration. Since there is no dead wood recruitment, the only direction for dead wood is towards emission/transfer (i.e., atmospheric emission or transfer to soil organic C) as decay rates may be high in moist, lower latitude forests [10].

\section{Conclusions}

Across the north central United States, forest detritus C pools are relatively static serving neither as a $C$ source nor as a sink. The flux status of DWM C pools should be monitored to determine its sensitivity to disturbance events or climate change. It appears that north central U.S. DWM C pools may greatly increase their sequestration rates through stand disturbance events, while $\mathrm{C}$ emission/transfer is often limited by slow decay rates (i.e., dead wood residence times). When considering most above-ground forest stand components and excluding the $\mathrm{C}$ balance complexities of stand conversion, the greatest sequestration rates may be found in younger stands in middle stages of stand development (e.g., stem exclusion or understory reinitiation) where branch shedding and shaded understories ensure dead wood retention, while the live trees accrue bole increment at relatively rapid rates. Overall, the DWM C flux dynamics of north central forests inherently depends on transfer from other stand components (e.g., standing live and dead pools) and does not guarantee an overall forest ecosystem sequestration if the residence time of $\mathrm{C}$ is decreased (i.e., increased CWD decay rates) or the sequestration capacity of other stand components is reduced (e.g., standing live tree species conversion or regeneration impairment).

\section{References}

[1] C. W. Woodall and V. J. Monleon, "Sampling, estimation, and analysis procedures for the down woody materials indicator," Tech. Rep. NRS-22, USDA Forest Service, Newtown Square, Pa, USA, 2008.

[2] L. S. Heath, J. E. Smith, and R. A. Birdsey, "Carbon trends in US forest lands: a context for the role of soils in forest carbon sequestration," in The Potential of US Forest Soils to Sequester Carbon and Mitigate the Greenhouse Effect, J. M. Kimble, L. S. Heath, R. A. Birdsey, and R. Lal, Eds., pp. 35-45, CRC Press LLC, Boca Raton, Fla, USA, 2003.

[3] EPA, "Inventory of U.S. greenhouse gas emissions and sinks: 1990-2006," Tech. Rep., U.S. Environmental Protection Agency, Washington, DC, USA, 2008.

[4] Y. Malhi, D. D. Baldocchi, and P. G. Jarvis, "The carbon balance of tropical, temperate and boreal forests," Plant, Cell \& Environment, vol. 22, no. 6, pp. 715-740, 1999.

[5] X. Yin, "The decay of forest woody debris: numerical modeling and implications based on some 300 data cases from North America," Oecologia, vol. 121, no. 1, pp. 81-98, 1999.

[6] J. Berry and O. Bjorkman, "Photosynthesis response and adaptation to temperature in higher plants," Annual Review of Plant Physiology, vol. 31, pp. 491-543, 1980.
[7] J. W. Raich, A. E. Russell, K. Kitayama, W. J. Parton, and P. M. Vitousek, "Temperature influences carbon accumulation in moist tropical forests," Ecology, vol. 87, no. 1, pp. 76-87, 2006.

[8] J. G. Hamilton, E. H. DeLucia, K. George, S. L. Naidu, A. C. Finzi, and W. H. Schlesinger, "Forest carbon balance under elevated $\mathrm{CO}_{2}$," Oecologia, vol. 131, no. 2, pp. 250-260, 2002.

[9] O. J. Sun, J. Campbell, B. E. Law, and V. Wolf, "Dynamics of carbon stocks in soils and detritus across chronosequences of different forest types in the Pacific Northwest, USA," Global Change Biology, vol. 10, no. 9, pp. 1470-1481, 2004.

[10] C. W. Woodall and G. C. Liknes, "Climatic regions as an indicator of forest coarse and fine woody debris carbon stocks in the United States," Carbon Balance and Management, vol. 3 , article 5, 2008.

[11] S. A. Hall, I. C. Burke, and N. T. Hobbs, "Litter and dead wood dynamics in ponderosa pine forests along a 160-year chronosequence," Ecological Applications, vol. 16, no. 6, pp. 2344-2355, 2006.

[12] D. M. Kashian, W. H. Romme, D. B. Tinker, M. G. Turner, and M. G. Ryan, "Carbon storage on landscapes with standreplacing fires," BioScience, vol. 56, no. 7, pp. 598-606, 2006.

[13] P. J. Radtke, S. P. Prisley, R. L. Amateis, C. A. Copenheaver, and H. E. Burkhart, "A proposed model for deadwood C production and decay in loblolly pine plantations," Environmental Management, vol. 33, supplement 1, pp. S56-S64, 2004.

[14] C. M. Gough, C. S. Vogel, C. Kazanski, L. Nagel, C. E. Flower, and P. S. Curtis, "Coarse woody debris and the carbon balance of a north temperate forest," Forest Ecology and Management, vol. 244, no. 1-3, pp. 60-67, 2007.

[15] J. E. Janisch and M. E. Harmon, "Successional changes in live and dead wood carbon stores: implications for net ecosystem productivity," Tree Physiology, vol. 22, no. 2-3, pp. 77-89, 2002.

[16] W. A. Bechtold and P. L. Patterson, Eds., "The enhanced forest inventory and analysis program-national sampling design and estimation procedures," Tech. Rep. SRS-80, USDA Forest Service, Asheville, NC, USA, 2005.

[17] U.S. Department of Agriculture, Forest Service, "Forest inventory and analysis national core field guide: field data collection procedures for phase 3 plots," Version 3.0, 2005, http://socrates.lv-hrc.nevada.edu/fia/dab/databandindex .html.

[18] M. E. Harmon, C. W. Woodall, B. Fasth, and J. Sexton, "Woody detritus density and density reduction factors for tree species in the United States: a synthesis," Tech. Rep. 29, USDA Forest Service, Northern Research Station, St. Paul, Minn, USA, 2008.

[19] J. A. Westfall and C. W. Woodall, "Measurement repeatability of a large-scale inventory of forest fuels," Forest Ecology and Management, vol. 253, no. 1-3, pp. 171-176, 2007.

[20] C. W. Woodall, L. S. Heath, and J. E. Smith, "National inventories of down and dead woody material forest carbon stocks in the United States: challenges and opportunities," Forest Ecology and Management, vol. 256, no. 3, pp. 221-228, 2008.

[21] C. W. Woodall and J. A. Westfall, "Relationships between the stocking levels of live trees and dead tree attributes in forests of the United States," Forest Ecology and Management, vol. 258, no. 11, pp. 2602-2608, 2009.

[22] S. Brown, "Measuring carbon in forests: current status and future challenges," Environmental Pollution, vol. 116, no. 3, pp. 363-372, 2002. 
[23] J. Q. Chambers, N. Higuchi, J. P. Schimel, L. V. Ferreira, and J. M. Melack, "Decomposition and carbon cycling of dead trees in tropical forests of the central Amazon," Oecologia, vol. 122, no. 3, pp. 380-388, 2000.

[24] O. N. Krankina and M. E. Harmon, "Dynamics of the dead wood carbon pool in northwestern Russian boreal forests," Water, Air, and Soil Pollution, vol. 82, no. 1-2, pp. 227-238, 1995.

[25] A. Knohl, O. Kolle, T. Y. Minayeva, et al., "Carbon dioxide exchange of a Russian boreal forest after disturbance by wind throw," Global Change Biology, vol. 8, no. 3, pp. 231-246, 2002.

[26] C. Wirth, E.-D. Schulze, B. Lühker, et al., "Fire and site type effects on the long-term carbon and nitrogen balance in pristine Siberian Scots pine forests," Plant and Soil, vol. 242, no. 1, pp. 41-63, 2002.

[27] C. W. Woodall and G. C. Liknes, "Relationships between forest fine and coarse woody debris carbon stocks across latitudinal gradients in the United States as an indicator of climate change effects," Ecological Indicators, vol. 8, no. 5, pp. 686-690, 2008.

[28] C. D. Oliver and B. C. Larson, Forest Stand Dynamics. Update Edition, John Wiley \& Sons, New York, NY, USA, 1996.

[29] L. Finér, H. Mannerkoski, S. Piirainen, and M. Starr, "Carbon and nitrogen pools in an old-growth, Norway spruce mixed forest in eastern Finland and changes associated with clearcutting," Forest Ecology and Management, vol. 174, no. 1-3, pp. 51-63, 2003. 

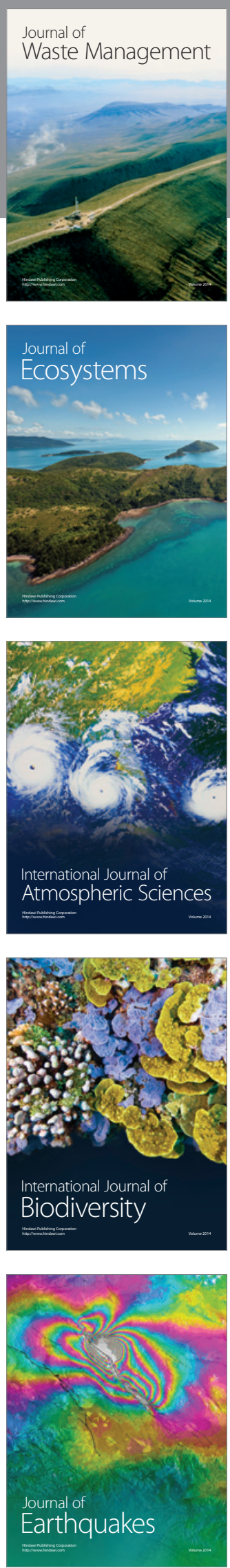
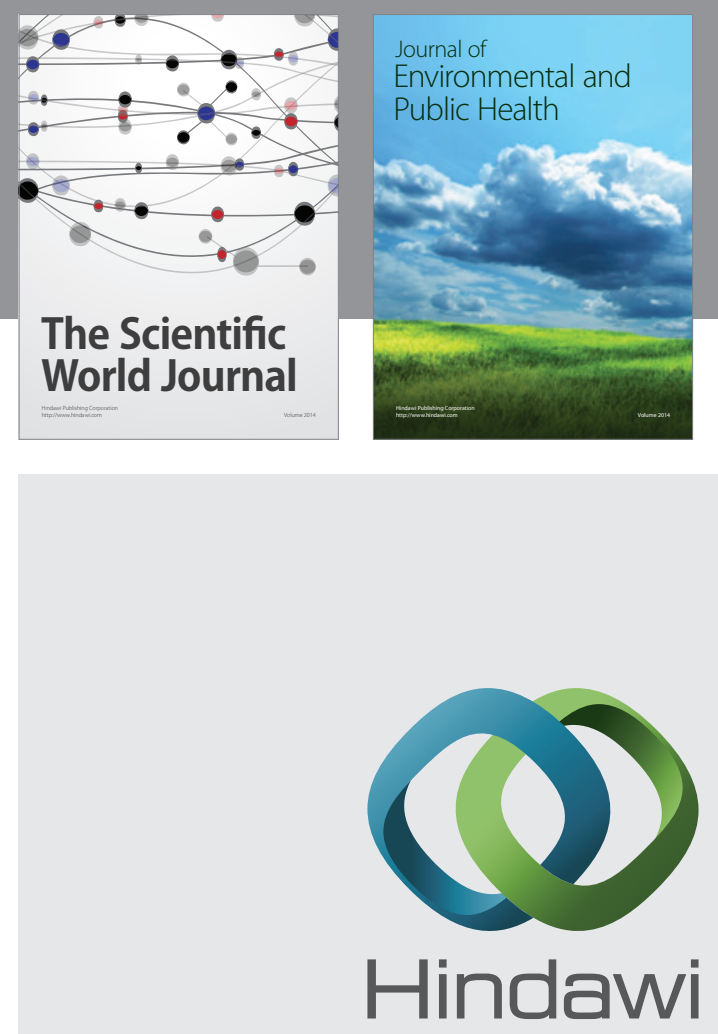

Submit your manuscripts at

http://www.hindawi.com
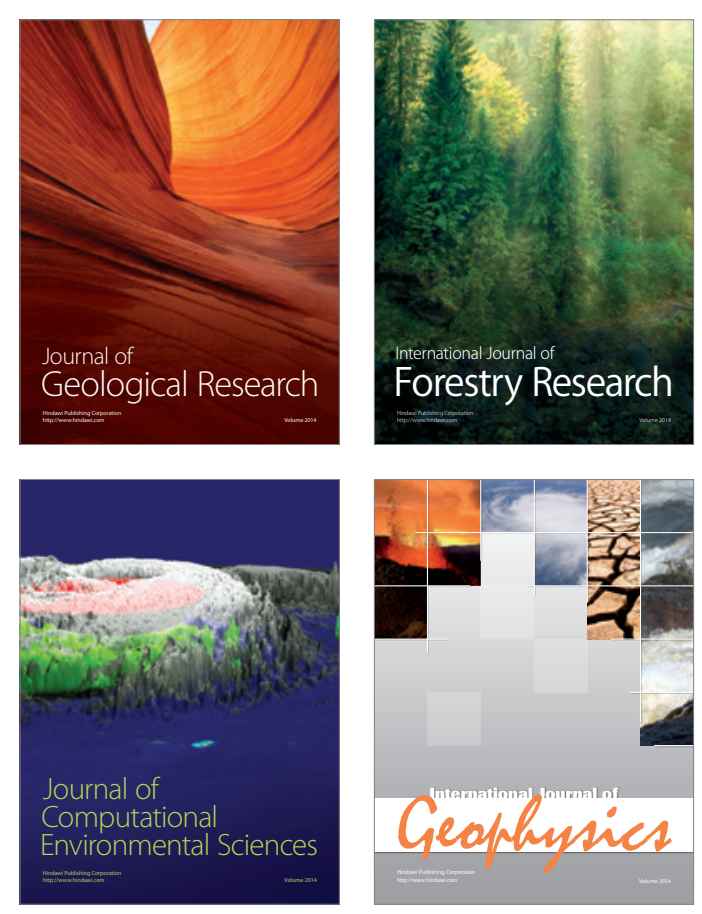
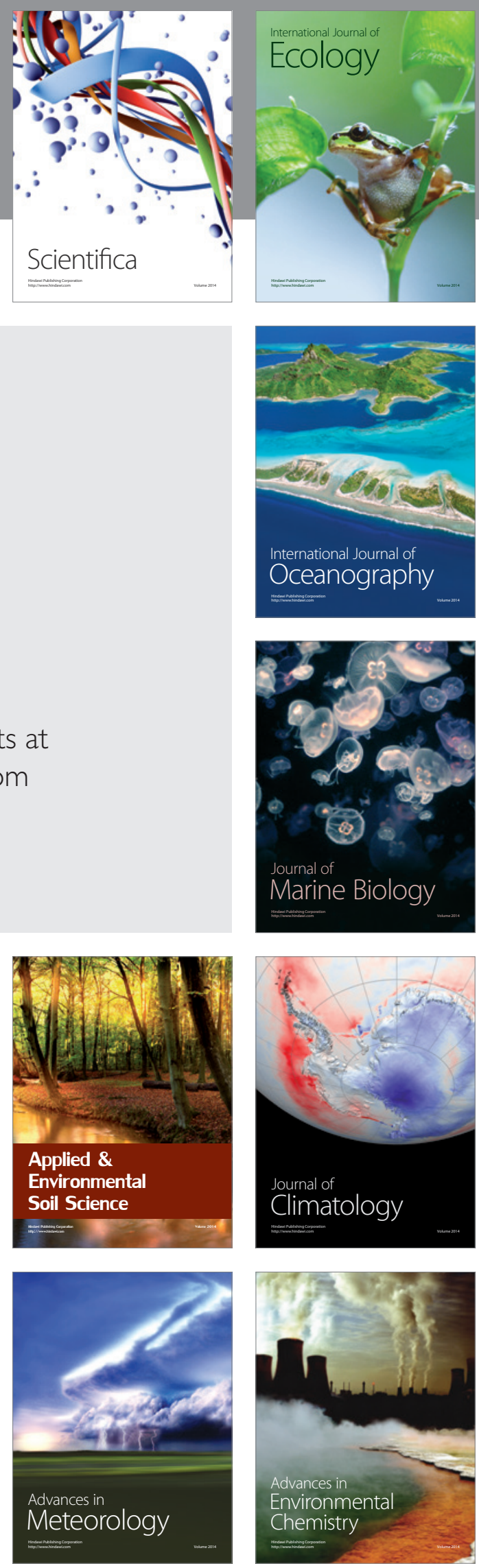